\title{
A TEORIA BIOECOLÓGICA DO DESENVOLVIMENTO HUMANO E SUAS RELAÇÕES COM A EDUCAÇÃO AMBIENTAL: UM ENSAIO SOBRE 'A VIAGEM DE CHIHIRO'
}

Rachel Munhoz

Resumo: A proposta deste trabalho é elaborar um ensaio sobre a metodologia da Teoria Bioecológica do Desenvolvimento Humano, de Urie Brofenbrenner, a partir da obra cinematográfica de animação japonesa "A Viagem de Chihiro". Além disso, colaborar com uma leitura para o campo da Educação Ambiental dentro da perspectiva crítica, destacando pontos como: antropocentrismo, questão de gênero, equilíbrio de poder, sistemas de cooperação e resistência. Assim, fortalecendo a potencialidade do cinema na área científica da EA.

Palavras-chave: Educação Ambiental; Brofenbrenner; Cinema. 


\section{Introdução}

A Viagem de Chihiro é uma animação japonesa lançada em 2001, do mais influente diretor do gênero, Hayao Miyazaki, vencedora do Urso de Ouro do Festival de Cinema de Berlim e também do Oscar de Melhor Animação em 2003. Conta a história de Chihiro Ogino, uma garota de dez anos que está de mudança para outra cidade, com o pai e a mãe. Durante a viagem de carro, eles/as" decidem parar diante de um obstáculo na estrada e é aí que Chihiro começa a sua aventura: a menina acaba presa em um mundo cheio de criaturas estranhas, espíritos e uma maldição que transforma sua família em porcos/as.

Chihiro nota que é dela a missão de salvar o seu mundo e a narrativa apresenta a história de seu amadurecimento: um processo de reconhecimento de sua própria força e de seu poder de resiliência, além da superação de um sistema mercantilista que a aliena de seu próprio ser. Por tratar da complexidade das influências recíprocas e de elementos contextuais no seu processo de desenvolvimento, a animação será interpretada a partir da Teoria Bioecológica do Desenvolvimento Humano, publicada por Urie Brofenbrenner (1970-1995). Por outro lado, por abordar um relacionamento mais amplo entre ser humano e natureza, valorizar os sistemas de cooperação, reprovar a ganância e valorizar as ações de resistência, este trabalho também pretende abrir novos diálogos dentro do campo da Educação Ambiental, a partir de autores/as como: Isabel Cristina de Moura Carvalho, Carlos Frederico B. Loureiro, Mauro Guimarães, Maria Angela Mattar Yunes e Maria Cristina Julino.

O objetivo desta proposta é, então, pensar sobre o desenvolvimento da protagonista do filme, a fim de ensaiar uma compreensão sobre a metodologia de Brofenbrenner, principalmente, pela constatação de que o trabalho com a Teoria Bioecológica do Desenvolvimento Humano a partir de obras cinematográficas é um nicho pouco praticado até o momento. A ideia é também abrir outras possibilidades de interlocução para o campo da Educação Ambiental, além de fortalecer a potencialidade do cinema na área científica.

\section{Fundamentação}

A Teoria Bioecológica do Desenvolvimento Humano trata da interação mútua entre indivíduos e das propriedades contextuais pelos quais eles/as se relacionam, sejam menos ou mais amplos, levando em conta também o tempo histórico em que se passam tais relações e as características de cada pessoa como peças importantes para o entendimento do processo de desenvolvimento psicológico. Essa abordagem teórico-metodológica de pesquisa foi criada pelo russo Urie Brofenbrenner, na década de 1970 e atualizada, em 1995, pelo próprio autor, destacando então o modelo PPCT (Processo - Pessoa - Contexto - Tempo). Com este novo olhar, a partir da relação entre os quatro aspectos do

\footnotetext{
" Utilizo o recurso da barra para linguagem inclusiva em todo o trabalho.
}

revista brasileira educação ambiental 
modelo apresentado, aumentam-se as chances de compreensão do fenômeno em estudo (BROFENBRENNER, 1996).

\section{Processo}

O primeiro aspecto do PPCT, Processo, é um dos mais importantes pontos do desenvolvimento, considerado como "a engrenagem principal do modelo" (TUDGE, 2008, p.3). Isso porque seria este o elemento que relacionaria os outros três aspectos, desta forma, é identificado como acontecimentos, atividades ou quaisquer outras ações em que as Pessoas participam em um determinado Contexto e por determinado Tempo. De maneira complexa, a pessoa interage com o seu mundo, transformando-o e transformando-se no processo. As formas de interação que ele/a mantém em seu ambiente imediato são chamadas de processos proximais (BROFENBRENNER, 1996).

Segundo o autor (1996, p.204):

A forma, o vigor, o conteúdo e a direção dos processos proximais que levam a cabo o desenvolvimento, variam sistematicamente como uma função conjunta das características da pessoa que se desenvolve; do ambiente tanto imediato quanto mais distante - no qual os processos ocorrem; da natureza dos aspectos do desenvolvimento estudados e das continuidades e mudanças sociais que acontecem ao longo do tempo no curso de vida e no período histórico durante o qual a pessoa viveu.

De acordo com Brofenbrenner (2011), os resultados dos processos proximais podem ser chamados de competências e ocorrem quando a pessoa em desenvolvimento passa a ter uma nova habilidade após a execução de uma atividade, ou seja, de um processo proximal. Assim como também pode passar a ter uma disfunção causada pela dificuldade de manter um comportamento, como por exemplo, insegurança para falar em público depois de sofrer forte pressão para fazê-lo. Originada nos processos proximais, a aquisição de competências deve ser somada aos outros aspectos do modelo PPCT para que haja uma compreensão mais abrangente.

\section{Pessoa}

Neste ponto do modelo PPCT, são abordados os atributos da pessoa em desenvolvimento, aqueles que são capazes de estimular ou evitar determinadas reações no ambiente em que ela está inserida. São estes mesmos atributos que provocam, ou deixam de provocar, os processos proximais mencionados acima. Para abordá-los, o autor da teoria usou três termos específicos: disposições, recursos e demandas (BROFENBRENNER, 2011).

Revbea, São Paulo, V. 12, № 5: 140-155, 2017. 
No primeiro, disposições, pode-se entender como aquilo que pode favorecer a pessoa em certas situações, tais quais: curiosidade, responsabilidade ou qualquer outro atributo que faça com que ela fique motivada a fazer algo. Paralelamente, alguns atributos que se encaixam neste termo podem ainda causar o efeito contrário, justamente, impedindo que a pessoa se sinta motivada, como: insegurança, distração e outros. Como recursos, pode-se entender características que promovam capacidades para a pessoa, como conhecimentos, biotipo físico, entre outros que podem facilitar a realização de alguma tarefa. Por último, sobre as demandas, pode-se compreender como os estímulos que cada pessoa possui para realizar uma ação em específico, por exemplo, seriam demandas: o gênero, a aparência física, raça, idade, entre outras.

Cada um dos três pontos mencionados pode interferir nas relações da pessoa em desenvolvimento, sendo essas suas características pessoais. Um aspecto muito importante a ser mencionado neste trabalho, que também é ressaltado por Brofenbrenner, é sua crença. Dependendo de seu sistema, ela pode ter uma forma específica para se posicionar diante de situações (BROFENBRENNER, 2011).

\section{Contexto}

Por contexto, entende-se as relações que ocorrem nos ambientes dos quais a pessoa participa, considerando que eles se relacionam e, dessa maneira, propiciam que os processos proximais aconteçam. Para conceituar os sistemas de cada ambiente, Brofenbrenner apresenta os seguintes termos: Microssistemas, Mesossistemas, Exossistemas e Macrossistemas. Assim, as interações que se originam em cada sistema compõem o contexto da pessoa em desenvolvimento.

A primeira camada do contexto é chamada de Microssistema, é onde ocorre a realidade cotidiana, juntamente com todas as pessoas que participam deste nível e, por isso, podem interferir de uma maneira mais efetiva no processo de desenvolvimento. Um exemplo de ambiente imediato é sua própria casa. A segunda camada, chamada de Mesossistema, pode ser entendida como as relações que ocorrem em diferentes microssistemas, por exemplo: uma interação entre os/as familiares da pessoa e o seu ambiente escolar ou de trabalho. A terceira camada, Exossistema, refere-se aos sistemas que podem intervir de uma maneira indireta na vida da pessoa em desenvolvimento. Por último, o Macrossistema, abrange as três primeiras camadas já mencionadas anteriormente e, por mais que não ocorram nela nenhum tipo de processo proximal, é onde há uma regulamentação ou padrão ideológico-institucional que afeta os outros sistemas (KOLLER, 2004). Um exemplo: o país em que se vive. 


\section{Tempo}

O último aspecto do modelo PPCT é considerado a partir do ponto de vista histórico e evolutivo pelo qual a pessoa em desenvolvimento irá passar. Assim, podem ser observados os processos proximais que ela tem ao longo do tempo e também o processo histórico no qual ela desenvolve tais relações.

Neste trabalho, a proposta é dar ênfase para o contexto da pessoa em desenvolvimento, neste caso, a protagonista da animação, Chihiro Ogino. Porém, como argumenta Koller (2004), para uma adequada investigação de um fenômeno na Teoria Bioecológica do Desenvolvimento Humano, todos os elementos devem ser considerados, valorizando, assim, a totalidade da realidade.

\section{Educação Ambiental}

Para Maria Angela Mattar Yunes e Maria Cristina Julino (2010), as possibilidades de interlocução entre a teoria de Urie Brofenbrenner e a Educação Ambiental estão, principalmente, nos seguintes pontos de convergência (2010, p.367):

o pensamento sistêmico; o foco nas interações de organismosambientes; a busca de compreensão sobre formas de cooperação entre indivíduos, grupos e comunidades e a construção de soluções que visualizam uma sociedade ecologicamente equilibrada.

Dessa forma, a partir de autores/as como Isabel Cristina Moura de Carvalho, Mauro Guimarães e Carlos Frederico B. Loureiro, muitos destes aspectos serão observados em uma perspectiva interacionista e sistêmica, assim, compreendendo a pessoa em desenvolvimento por sua constante interação entre os seus diferentes contextos sociais e culturais.

Outro ponto interessante a ser ressaltado, é que a animação $A$ Viagem de Chihiro contribui com o seleto grupo de obras que não perpetuam uma visão antropocêntrica, machista e com relações de poder desequilibradas, entre os outros aspectos considerados comos os pilares da crise ecológica (GUIMARÃES, 2004), possibilitando outros diálogos entre seus/suas espectadores/as e, ainda, servindo como um importante material pedagógico dentro do campo da Educação Ambiental.

O objetivo deste trabalho é elaborar considerações sobre cada aspecto observado no longa metragem, relacionando cada um deles com a bibliografia de Brofenbrenner, além de consultar também outros/as autores/as que trabalham com a mesma metodologia de pesquisa, a exemplo de Silvia Koller (2004) e Jonathan Tudge (2008). 


\section{Metodologia}

A partir da Teoria Bioecológica do Desenvolvimento Humano, de Urie Brofenbrenner, e dos fundamentos da Educação Ambiental que dialogam com a mesma, os quatro aspectos do modelo PPCT serão considerados por meio de passagens descritas do longa metragem de animação.

Para tanto, por mais que os quatro elementos não possam ser indissociados, serão abordados de forma isolada para efeitos de compreensão, sendo assim, apontando os processos que fazem parte do longa metragem de animação e a carga emocional que cada um deles efetivou na personagem. Em se tratando das propriedades da pessoa, será possível conhecer um pouco mais da protagonista, para que suas reações, assim como as reações das pessoas que se relacionam com ela entre os processos proximais, sejam compreendidos de maneira abrangente.

O contexto, neste trabalho, receberá um recorte específico. Por isso, será possível saber com mais detalhes os cenários que compõem o Macrossistema, Exossistema, Mesossistema e Microssistema na história do desenvolvimento de Chihiro. Além disso, serão ilustradas as principais díades primária, de observação e de atividade conjunta - originadas nos processos proximais aos quais ela participa, apontando cada personagem do filme. $O$ tempo também será considerado, valorizando, assim, os quatro aspectos do modelo PPCT proposto por Urie Brofenbrenner.

Como esta proposta carrega também a missão de contribuir para estudos da Educação Ambiental, será realizada uma leitura da animação a partir dos fundamentos deste campo do conhecimento, marcando, principalmente, os termos: antropocentrismo, questão de gênero, equilíbrio de poder, sistemas de cooperação e resistência.

\section{Discussão}

Nesta proposta de trabalho, a ideia é dirigir a atenção não somente às propriedades da pessoa em desenvolvimento e aos ambientes imediatos dos quais ela participa. Como estimulado pela Teoria Bioecológica do Desenvolvimento Humano, de Urie Brofenbrenner, serão consideradas também as interações que ocorrem na história de Chihiro Ogino - personagem principal da animação $A$ Viagem de Chihiro - com foco especial para as transições pelos ambientes.

A sequência de eventos que ocorrem com a protagonista ao se mudar com a família para outra cidade faz com que ela se confronte com o seu potencial de resiliência para sobreviver diante de muitas situações de risco às quais ela acaba ficando exposta. Para abordar ainda melhor o assunto, inicialmente, se faz necessário um breve resumo do filme e sobre as principais características pessoais da menina, atributos que dificultaram e também favoreceram uma série de reações, além de, inevitavelmente, provocar situações que promoveram o seu amadurecimento.

revista brasileira educação ambiental 
A premissa do filme é o deslocamento da família Ogino para outra cidade, totalmente desconhecida. Eles/as chegam ao novo lugar de carro, porém, na estrada, se deparam com um túnel que parece bastante misterioso. O pai e a mãe, curiosos/as, são estimulados/as a descer do carro e explorar o novo local, enquanto a menina, insegura, prefere sair de lá o mais depressa possível. Afinal, ela não sente nenhum tipo de pertencimento àquele lugar ou algum tipo de reconhecimento que torne possível se sentir mais à vontade. Todos/as adentram ao túnel, a menina agarrada ao braço de sua mãe, que pede que ela seja mais confiante. Quando observam uma série de casas decoradas, consideram que aquele seja um dos parques temáticos que faliram nos anos 1990, em Tóquio.

Os/as três caminham pelo lugar até que encontram um restaurante vazio, mas com pratos preparados e expostos no balcão. $O$ pai e a mãe não pensam em outra coisa, senão comer tudo que ali está e deixar para pagar quando alguém aparecer - neste caso, a impulsividade dos/as dois faz com que tomem uma decisão que, posteriormente se descobre, é ruim. Já Chihiro, com tamanha insegurança, prefere não tocar em nada e, assim, acaba por ser a única que não foi amaldiçoada. Ao cair da noite, a cidade abandonada se transforma, as luzes acendem e o lugar fica repleto de espíritos e criaturas fantásticas e assustadoras. O pai e a mãe são transformados/as em porcos/as por terem se alimentado de uma comida mágica.

Chihiro fica em pânico e é justamente nesta hora de crise que ela conhece Hako, o menino que se transforma em dragão e que, antes de ser amaldiçoado, era um rio. Ele explica que aquele mundo possui regras específicas e auxilia sua entrada na Casa de Banho - comércio que mantém todo o parque. Para permanecer por lá, é preciso que ela consiga um emprego, além de seguir outras normas locais. Entre as várias situações que ocorrem a seguir, a menina acaba conhecendo um cliente que pode produzir ouro, o Espírito Sem Rosto, porém, ela está tão comprometida com os seus objetivos, de salvar a sua família, que não vê utilidade alguma no dinheiro naquele momento. A simplicidade dela chama a atenção do cliente, que acaba por punir todos/as aqueles/as que foram gananciosos/as.

Neste ponto, é possível notar que as características pessoais de cada um/a fez com que tomassem diferentes decisões, obtendo diferentes resultados. Enquanto os/as dois adultos/as se sentiam mais confiantes e seguros/as, seus atributos permitiram que eles/as comessem de tudo sem se preocupar. Pode-se notar a tranquilidade do pai ao dizer à menina: "calma, seu papai está aqui e eu tenho cartão de crédito". Ele é um dos pilares de poder daquela família e desempenha com confiança a atitude de se alimentar, pois pode pagar. Por outro lado, a menina, medrosa, reúne outros tipos de atributos, os quais, neste caso, a protegem da maldição.

A narrativa do filme mostra que Chihiro é filha única do jovem casal e, tanto o pai, como a mãe, são bastante cuidadosos/as com a filha. Esse contexto, certamente, estimulava que a menina de apenas dez anos reagisse de determinada maneira diante de dificuldades, com a segurança da presença Revbea, São Paulo, V. 12, № 5: 140-155, 2017. 
de seus/suas familiares e o sentimento de pertencimento que ela possuía em seu antigo lar e comunidade. Ao agarrar o braço de sua mãe, com medo, fica claro que algumas de suas características pessoais podem ser: falta de autonomia, falta de coragem para superar seus medos, por exemplo, de ficar sozinha, entre outras coisas.

Neste momento, ela passa por uma transição de ambientes com relação à mudança para outra cidade. Isso, por si só, já provoca grande estresse na menina, que aparenta estar muito insatisfeita com tais modificações, ela não sabe o que esperar da nova casa, novo bairro e, principalmente, da nova escola. Durante a viagem de carro, obtém-se pistas com relação ao sistema de crenças do lugar e, que por algum estímulo pessoal da própria garota, podem ter provocado a fantasia que é parte principal do filme. No caminho até o túnel, é possível notar diversos monumentos de deuses em pedras e pequenas casinhas que fazem parte de um antigo santuário onde as pessoas acendiam velas e realizavam orações.

Com sua família transformada em porcos/as, Chihiro se vê sozinha em um mundo fantástico. Este é o primeiro evento histórico que se pode destacar: o enfrentamento do medo em estar só, uma situação que irá motivá-la a ter uma série de reações diante de seus novos processos proximais. Com a situação apresentada, pode ser criado o modelo de estudo do desenvolvimento de Chihiro.

\section{Modelo PPCT}

O modelo PPCT é representado por: Pessoa - Processo - Contexto Tempo. Sendo o contexto o recorte principal deste trabalho, sua descrição receberá maior enfoque mais adiante.

Sendo o aspecto processo identificado como os eventos que ocorrem com a pessoa em desenvolvimento, pode-se dizer que entre os principais processos em $A$ Viagem de Chihiro, responsáveis por ocasionar as relações proximais da pessoa no contexto, por determinado tempo, são: a) a mudança da família para uma nova cidade; b) ingresso em um parque temático que é, na verdade, um mundo fantástico; c) a maldição da família; d) conquista do emprego; e) por último, salvamento de Hako e de sua família. Cada processo ocasionou uma série de outros processos que se complexificaram progressivamente e a menina interage e participa de cada um deles de maneira a se modificar e modificar tudo ao seu redor. Não há dúvida de que essas situações, que efetivam cargas positivas e negativas sob a menina, influenciaram a dinâmica de seu desenvolvimento.

O evento "a", mudança da família para uma nova cidade, por exemplo, propiciou que todos os outros acontecessem, por isso tem tamanha importância na escala de eventos históricos do filme, assim como o evento "b", ingresso no parque - ambos promovendo grandes cargas emocionais, nestes casos, mais negativas. Já o "c", maldição da família, foi um acontecimento de especial carga negativa e poderia ter exercido uma influência que resultasse 
em disfunções para Chihiro, não fosse o seu encontro com Hako - sua principal díade primária. O evento " $d$ ", conquista do emprego, tornou-se positivo com o sucesso da empreitada, pois Chihiro passa a adquirir uma série de novos atributos. O ocorrido "e", salvamento da família e do amigo, como se trata de uma fase final do longa metragem, já se passa com a personagem bastante modificada, ou seja, ela já dispõe de novas características para o enfrentamento de seus obstáculos e grande poder de resiliência.

Entre as propriedades da pessoa de Chihiro Ogino, é possível perceber que seu sistema de crenças oferece a disposição necessária para que ela acredite na aventura que está prestes a ter, estimulada pelas estátuas de pedra que encontrou no caminho até o túnel. Outra característica que tem a ver com este termo é sua falta de confiança, algo que a faz pensar um pouco mais antes de realizar qualquer ação, o que, neste caso, fez com que ela escapasse de ser amaldiçoada junto com a sua família. Entre os recursos da menina, a ausência de ganância com relação ao ouro oferecido pelo cliente misterioso também a destaca entre todos/as os/as funcionários/as da Casa de Banho, fazendo com que ela conquistasse um novo amigo e protetor, o Espírito Sem Rosto.

Sobre as demandas, é possível apontar a necessidade que ela tinha de se identificar com alguém naquele mundo desconhecido, de estabelecer um elo de ligação, de ordem afetiva, para que pudesse se sentir mais segura, levando em conta a sua idade. Essas eram as características de Chihiro no início do longa metragem e promoveram as situações que estimularam o seu desenvolvimento, além de evitar que determinadas ações acontecessem. A pessoa é um/a ser biopsicológico/a e, além de produtor/a indireto/a, é também um produto de seu próprio desenvolvimento, como explica Brofenbrenner (1992, p. 225, In COPETTI; KREBS, 2004, p. 72):

Nenhuma característica da pessoa existe ou exerce influência no desenvolvimento de forma isolada. Cada qualidade humana é intricadamente envolvida e encontra os seus significados e mais profundas expressões em ambientes particulares [...]. Como resultado, há sempre um entrejogo entre as características psicológicas da pessoas e as de um ambiente específico, uma não pode ser definida sem referência à outra.

O estudo do contexto recebe maior tratamento a seguir. E o último aspecto, o tempo, é considerado por autores/as como Alves (2002) "um organizador emocional e social, uma vez que abrange, na dinâmica do desenvolvimento humano, a existência de grandes eventos históricos pertinentes" (ALVES, 2002, In SILVA; ALVES; KOLLER; 2004, pág.145). Neste estudo de caso, como trata-se de uma espécie de sonho ou fantasia, o tempo parece ser mais longo do que verdadeiramente é, por isso, a transição ecológica que é um grande evento histórico para a personagem é bastante significativo e capaz de influenciá-la de forma efetiva.

Revbea, São Paulo, V. 12, № 5: 140-155, 2017. 


\section{Recorte da proposta: Contexto}

O macrossistema é configurado em um ambiente maior, que reúne todos os outros sistemas. Neste ambiente, não ocorrem processos proximais, porém é a partir dele que todos os outros sistemas são regulados. Nas palavras de Brofenbrenner (2011, p. 150):

É todo um padrão conjunto de microssistemas, mesossistemas e exossistemas característicos de uma dada cultura, subcultura ou outro contexto social maior, com um particular referencial desenvolvimentista investigativo para o sistema de crenças, recursos, riscos, estilos de vida, estruturas, oportunidades, opções de vida e padrões de intercâmbio social que estão incluídos em cada um destes sistemas.

Em $A$ Viagem de Chihiro, o macrossistema da menina passa a ser a "Casa de Banho em que 8 milhões de deuses vão para descansar", local que sustenta o parque temático em questão. Lá, existem normatizações que devem ser seguidas por todos/as: cada um/a deve desempenhar uma função para que não seja amaldiçoado/a; todos/as recebem um novo nome e só podem sair de lá ao recuperarem o seu nome original; e, além disso, o/a chefe do local precisa dar trabalho a todos/as que o pedem. Essas são as normas sob as quais vivem as personagens do filme.

Já o exossistema é composto pelos lugares em que as decisões são tomadas, para Koller (2004), são como centros de poder, enquanto Brofenbrenner explica da seguinte maneira (1996, p. 227):

O exossistema rodeia a ligação e os processos que tem lugar entre dois ou mais ambientes, no mínimo um deles não contém necessariamente a pessoa em desenvolvimento, mas no qual eventos acontecem que podem influenciar processos dentro do ambiente imediato que contém a pessoa (por exemplo, para a criança, a relação entre a casa e o local de trabalho dos pais; para um pai a relação entre a escola e o grupo de vizinhos.

A regulamentação da Casa de Banho é representada na figura da bruxa má, Yubaba, por isso, ao Chihiro insistir que quer um trabalho, ela se vê obrigada a colocar a menina para desempenhar uma função qualquer, por mais que ela aparente ser "fraca e burrinha". Ela é a irmã gêmea de Zeniba, a bruxa boa, as duas bruxas são as responsáveis pelo desencadeamento de uma série de fatores que movimentam a transição ecológica da menina. Neste ponto, pode-se considerar que estas personagens e todos/as os/as seus/suas aliados/as fazem parte do Exossistema no contexto da protagonista. 
Neste sentido, o trabalho de Chihiro como ajudante de limpeza e todas as suas responsabilidades diárias, juntamente com todos/as os/as seus/suas colegas de trabalho, passam a compor um novo microssistema. Assim como também é um microssistema o seu relacionamento com Hako, que ela conhece logo no início de sua jornada e com quem ela tem uma relação de reciprocidade, afeto e equilíbrio de poder. Assim, o diálogo entre os dois microssistemas: a) seu relacionamento com Hako, alguém que representa segurança social, psíquica e física; b) seus/suas colegas de trabalho e suas novas responsabilidades, que provocam situações em que ela pode aprender valores éticos, vencer seus medos e adquirir novas habilidades; formam o seu Mesossistema. De acordo com o autor (2011, p.146):

Compreende as ligações e processos que tem lugar entre dois ou mais ambientes que contém a pessoa em desenvolvimento (por exemplo as relações entre a casa e a escola, escola e trabalho, etc). Em outras palavras, um mesossistema é um sistema de microssistemas.

Entre os novos microssistemas que foram criados a partir de seu ingresso no mundo fantástico da Casa de Banho, e já mencionados no texto acima, pode-se destacar algumas características que compõem esse conceito. Porém, antes de esmiuçá-las, vale lembrar a definição desta camada pelas palavras do autor( 1996, p. 226):

Um microssistema é um padrão de atividades, papéis e relações interpessoais experimentados pela pessoa em desenvolvimento em um dado ambiente com características físicas e materiais particulares e que contém outras pessoas com características distintas de temperamento, personalidade e sistema de crenças.

O nível mais imediato da pessoa é onde ela constrói os vínculos mais importantes para o seu desenvolvimento, chamados de díades, nas quais devem existir: reciprocidade, equilíbrio de poder e afetividade, este último positiva ou negativamente. As díades são representadas de três formas diferentes na Teoria Bioecológica do Desenvolvimento Humano:

- A díade primária é uma relação que, de tão marcante para a pessoa em desenvolvimento, continua existindo mesmo em memória, quando as duas pessoas já não estão mais juntas. A interação entre Chihiro e Hako representa bem esta díade, pois há um reciprocidade de sentimentos, grande afeto positivo e equilíbrio de poder, apresentado pelo fato de que um/a salva a vida do/a outro/a, mostrando que os/as dois/duas são capazes de grandes feitos. Ao final da animação, é notável que Chihiro jamais esquecerá o amigo. 
- A díade de atividade conjunta é, como o nome já diz, uma interação em que duas pessoas executam uma atividade juntas. Neste caso, podemos destacar a interação entre Chihiro e Lin, uma ajudante de limpeza mais experiente que ensina tudo para a garota e divide com ela a função de dar banho nos/as clientes, além de limpar todo o local. A relação entre as duas faz com que a menina adquira uma série de outras habilidades, desenvolvendo mais confiança em seu potencial.

- Já a díade de observação se dá quando a pessoa em desenvolvimento apenas observa a execução de uma atividade, demonstrando interesse e tendo este sentimento reconhecido pelo/a outro/a que efetiva a ação. A personagem Kamaji, uma espécie de aranha responsável por designar certas funções na Casa de Banho, trabalha na caldeiraria. Chihiro o observa com bastante interesse para aprender a tarefa, afinal nesta fase do longa metragem ela está desesperada para conquistar um posto de trabalho.

Todas as interações que ocorrem entre os vários ambientes fazem com que o Mesossistema influencie o desenvolvimento da personagem e viceversa, pois ela passa a interagir, ativamente, por eles. Além disso, há intervenção indireta do Exossistema e do Macrossistema durante todo o curso de suas atividades. Nessa migração entre sistemas, constata-se a constituição de novos processos proximais, por assim dizer, de pessoas, símbolos e ações. $\mathrm{E}$ tudo isso é possível porque Chihiro passa a conquistar relações de reciprocidade, tanto com seu novo amigo Hako, quanto com seus/suas colegas de trabalho, como Lin e Kamaji, e alguns/mas clientes da Casa de Banho, como o Espírito Sem Rosto. Tais relações são de extrema importância para a aquisição das novas habilidades: resolução de problemas; execução de tarefas complexas; autonomia para fazer coisas de forma independente; entre outros.

\section{Educação Ambiental}

A citação a seguir, de Urie Brofenbrenner, ilustra alguns pontos de convergências entre a Teoria Bioecológica do Desenvolvimento Humano e alguns dos fundamentos da Educação Ambiental (1999, p.44-45 In YUNES; JULINO, 2010, p.22):

Esta consciência planetária crescente nos faz cidadãos do mundo e não apenas deste ou daquele país. Vivemos uma comunidade de destino; o destino da espécie humana está associado indissoluvelmente ao destino do planeta e do cosmos. Qualquer antropocentrismo está fora do lugar.

Assim, as autoras Maria Angela Mattar Yunes e Maria Cristina Julino apontam que (2010, p. 22): 
Pode-se afirmar que a ecologia e a bioecologia do desenvolvimento humano também propõe uma educação que desloca 0 ser humano da posição de onipotência antropocêntrica para integrar a posição de componente do todo, configurado como espaço psicológico ou espaço vital pelos objetos, pessoas e acontecimentos aos quais a pessoa atribui significado.

Neste sentido, pode-se observar que a narrativa da animação $A$ Viagem de Chihiro também propõe este mesmo deslocamento. Primeiro, da posição de onipotência antropocêntrica, quando coloca as personagens ser humana (Chihiro) e humano/rio/dragão (Hako) no mesmo nível de importância, inclusive, atuando juntos/as, por mais que, em alguns momentos, a personagem tenha forma humana para interagir com a menina. Vale lembrar que a história dos/as dois/duas é antiga, desde quando o garoto vivia apenas em forma de água. Tal conceito artístico, que pode ter sua inspiração na cosmogonia japonesa, empresta ao filme também uma visão socioambiental, em que "a natureza, os humanos, bem como a sociedade e o ambiente, estabelecem uma relação de mútua interação e co-pertença, formando um único mundo" (CARVALHO, 2004, p. 36).

Em segundo lugar, o filme também desloca outro tipo de comportamento que é combatido pelos/as autores/as da Educação Ambiental, a perpetuação de uma visão machista. Ao colocar uma personagem feminina como protagonista que, ao passar por uma fase de desenvolvimento psicológico, torna-se tão forte e corajosa a ponto de salvar sua família e seu amigo, elabora uma obra de arte que tem grande potencial pedagógico e valiosos ensinamentos ambientais. Afinal, assim como a visão antropocêntrica, a questão de gênero desequilibrada compõe os pilares da crise ecológica (GUIMARÃES, 2004). E àqueles que possuem a opinião de que Chihiro somente desenvolveu tamanha coragem por amor à Hako, vale lembrar que as vidas de seu pai e de sua mãe, assim como a sua própria sobrevivência, dependiam dela, isto é, das interações que ocorriam a partir dela.

Este último apontamento, sobre as interações, leva ao próximo ponto sobre as convergências entre os/as autores/as: o pensamento sistêmico. Durante todo o filme, os/as espectadores/as podem perceber que tudo que Chihiro realiza tem ligação direta com os ensinamentos de outras personagens. Ela é uma menina corajosa, mas só percebe isso quando sua família precisa de ajuda e, para tanto, ela conta com o auxílio de diversos outros sistemas de interações: o envolvimento de Hako com Yubaba; os ensinamentos de Lin por meio de sua ligação com Kamaji; o núcleo coadjuvante da irmã gêmea Zeniba; entre outros organismos de interações que participam, direta ou indiretamente, do seu desenvolvimento. Todos esses sistemas que cooperaram com 0 amadurecimento de Chihiro favoreceram a construção de soluções, fazendo com que a menina possa adquirir novas habilidades, competências (BROFENBRENNER, 2011), e possa chegar até a reta final de sua missão: o 
salvamento do amigo Hako e de sua família. Desta forma, imprimindo uma mensagem sobre a importância do potencial coletivo para a transformação do mundo e valorização de diferentes saberes, "(...) alargando a nossa visão do ambiente e captando os múltiplos sentidos que os grupos sociais atribuem à ele" (CARVALHO, 2004, p.125).

Como já mencionado anteriormente, o equilíbrio de poder é um importante elemento nas díades primárias, a exemplo da díade formada por Chihiro e Hako, na teoria de Brofenbrenner. Para o autor (1996, p. 47):

há evidências sugerindo que a situação ótima para aprendizagem e o desenvolvimento é aquela em que o equilíbrio do poder gradualmente se altera em favor da pessoa em desenvolvimento, em outras palavras, quando esta última recebe uma crescente oportunidade de exercer controle sobre a situação.

Essa visão pode ser encontrada também nos discursos da Educação Ambiental em uma perspectiva crítica, que busca igualdade como condição da afirmação das diferenças no processo de definição de valores.

Outro ponto interessante a se destacar na animação é a posição da menina diante do ouro oferecido pelo cliente Espírito Sem Rosto, algo que a diferencia dos/as demais e impede que ela seja engolida por ele. A analogia sobre a conquista de seus desejos por uma via alternativa à sociedade capitalista é inevitável, outro fator que vai de encontro com a Educação Ambiental crítica (LOUREIRO, 2012).

Ainda neste ponto, é importante ressaltar também a relação entre a menina e o trabalho construída ao longo do filme. Chihiro é obrigada a trabalhar na Casa de Banho como ajudante de limpeza para que possa sobreviver - aqui, não se fala somente de sobrevivência natural, de um corpo que precisa se alimentar, entre outras coisas. Na verdade, ela precisa trabalhar para que não suma, de maneira literal, afinal o lugar é encantado. Para isso, ela perde o seu próprio nome e passa a se chamar Sem. Sem a posse de seu nome original, ela não pode abandonar o mundo fantástico, porém, quanto mais o tempo passa, mais ela se afasta dessa possibilidade, pois é levada ao esquecimento. Neste sentido, é possível relacionar com as concepções marxistas sobre a alienação do trabalho, teoria que é comumentemente ligada à Educação Ambiental crítica, pois, de acordo com Loureiro, "a construção de caminhos que buscam a superação do atual processo de produção destrutiva e mercantilização da vida, inerentes às relações sociais no capitalismo" (2009, p. 92).

Por fim, as formas de resistência de uma personagem feminina diante das práticas de dominação, por meio de uma rede de cooperação entre diversas personagens, com diferentes saberes, além do deslocamento da 
posição antropocêntrica, colocam a animação $A$ Viagem de Chihiro entre as obras audiovisuais de grande relevância para o campo da Educação Ambiental.

\section{Considerações finais}

De acordo com Urie Brofenbrenner, para que ocorra desenvolvimento psicológico saudável é necessário que ocorram interações marcadas por sentimentos positivos, reciprocidade e equilíbrio de poder. A Viagem de Chihiro é uma animação focada, justamente, no amadurecimento da protagonista a partir das interações que ela produz, e pelas quais é produzida, valorizando cada uma dessas relações como importantes sistemas de cooperação; os diferentes saberes de cada personagem; priorizando, entre outros elementos, o equilíbrio de poder; e outros.

A sequência do filme é ilustrada pelo desenvolvimento da menina: um processo de reconhecimento de sua própria força e de seu poder de resiliência, necessários para salvar sua família e seu amigo e a superação de um sistema capitalista que a aliena de seu próprio ser. Neste ínterim, apresenta o relacionamento entre ser humano e a natureza de maneira mais ampla, utilizando-se de uma visão socioambiental, contando com uma personagem feminina para todo este processo.

Com esta discussão, a intenção é contribuir com o entendimento sobre a dinâmica do desenvolvimento e compartilhar com este campo a partir de artefatos culturais de gênero cinematográfico na intenção de fortalecer a potencialidade do cinema na área científica. Outra pretensão é seguir com estudos que estejam conectados com a área de Educação Ambiental, por identificar que seja este um dos caminhos de grande relevância para a transformação da sociedade.

\section{Agradecimentos}

À professora dr.. Narjara Mendes Garcia, da Universidade Federal do Rio Grande - PPGEA/FURG, pela oportunidade de participação na disciplina Abordagem Ecológica do Desenvolvimento Humano e inspiração para o artigo.

\section{Referências}

A VIAGEM de Chiro. Direção: Hayao Miyazaki. Japão: Studio Ghibli, 2001.125 $\min$.

BRONFENBRENNER, U. A Ecologia do Desenvolvimento Humano: Experimentos Naturais e Planejados. Porto Alegre: Artes Médicas, 1996..

BROFENBRENNER, U. Bioecologia do desenvolvimento humano: tornando os seres mais humanos; tradução técnica: André de Carvalho - Barreto. Porto Alegre: Artmed, 2011. 
GUIMARÃES, M. A formação de educadores ambientais. Campinas, SP: Papirus (Coleção Papirus Educação) 2004.

KOLLER, S H. Conversando com Bronfenbrenner. In: KOLLER, S.H. (org). Ecologia do Desenvolvimento Humano. Pesquisa e Intervenção no Brasil. São Paulo: Casa do Psicólogo, 2004, p 43-51.

LOUREIRO, C.F.B. Trajetória e Fundamentos da Educação Ambiental. São Paulo: Cortez, 2012.

LOUREIRO, C.F.B. Contribuições da teoria marxista para a educação ambiental crítica. Cad. Cedes, Campinas, vol. 29, n. 77, p. 81-97, jan./abr. 2009. Disponível em: <http://www.scielo.br/pdf/ccedes/v29n77/a06v2977.pdf.> Acesso em: 29 de jun. 2017.

POLETTO, M; KOLLER, S.H. Contextos ecológicos: promotores de resiliência, fatores de risco e de proteção. Estudos de psicologia, v. 25, 2008.

TUDGE, J. A teoria de Urie Bronfenbrenner: uma teoria contextualista? In: MOREIRA, L; CARVALHO, A.M. Família e Educação: olhares da psicologia. São Paulo: Paulinas, 2008.

YUNES, M.A.M; JULIANO, M.C. A bioecologia do desenvolvimento humano e suas interfaces com educação ambiental. Cadernos de Educação, n. 37, 2010. 